\title{
Less healthy, but more active: Opposing selection biases when recruiting older people to a physical activity study through primary
}

\section{care}

\author{
Tess J Harris*1,2, Christina R Victor ${ }^{3}$, Iain M Carey ${ }^{1}$, Rika Adams ${ }^{2}$ and \\ Derek G Cook ${ }^{1}$
}

\begin{abstract}
Address: ${ }^{1}$ Division of Community Health Sciences, St George's, University of London, Cranmer Terrace, Tooting, London, SW17 ORE, UK, 2Sonning Common Health Centre, Wood Lane, Sonning Common, Oxfordshire, RG4 9SW, UK and ${ }^{3}$ School of Health and Social Care, Reading University, Whiteknights Lane, Reading, Berkshire, UK

Email: Tess J Harris* - tharris@sgul.ac.uk; Christina R Victor - c.r.victor@reading.ac.uk; Iain M Carey - i.carey@sgul.ac.uk; Rika Adams - Rika.Adams@gp-K84020.nhs.uk; Derek G Cook - d.cook@sgul.ac.uk

* Corresponding author
\end{abstract}

\section{Published: 27 May 2008}

BMC Public Health 2008, 8:182 doi:10.1 I86/147|-2458-8-182
Received: II January 2008

Accepted: 27 May 2008

This article is available from: http://www.biomedcentral.com/I47I-2458/8//82

(c) 2008 Harris et al; licensee BioMed Central Ltd.

This is an Open Access article distributed under the terms of the Creative Commons Attribution License (http://creativecommons.org/licenses/by/2.0), which permits unrestricted use, distribution, and reproduction in any medium, provided the original work is properly cited.

\begin{abstract}
Background: Physical activity studies in older people experience poor recruitment. We wished to assess the influence of activity levels and health status on recruitment to a physical activity study in older people.
\end{abstract}

Methods: Comparison of participants and non-participants to a physical activity study using accelerometers in patients aged $\geq 65$ years registered with a UK primary care centre. Logistic regression was used to calculate odds ratios (OR) of participants in the accelerometer study with various adjustments. Analyses were initially adjusted for age, sex and household clustering; the health variables were then adjusted for physical activity levels and vice versa to look for independent effects.

Results: $43 \%(240 / 560)$ participated in the physical activity study. Age had no effect but males were more likely to participate than females OR I.4(I.I-I.8). 46\% (76/I64) of non-participants sent the questionnaire returned it. The 240 participants reported greater physical activity than the 76 nonparticipants on all measures, eg faster walking OR 3.2(1.4-7.7), or 10.4(3.2-33.3) after adjustment for health variables. Participants reported more health problems; this effect became statistically significant after controlling for physical activity, eg disability OR 2.4(I.I-5.I).

Conclusion: Physical activity studies on older primary care patients may experience both a strong bias towards participants being more active and a weaker bias towards participants having more health problems and therefore primary care contact. The latter bias could be advantageous for physical activity intervention studies, where those with health problems need targeting.

\section{Background}

Physical activity studies on older people often recruit through primary care, such studies usually report low par- ticipation, both for surveys (46\% [1], 57\% [2]) and more markedly for intervention studies (26\% [3], 32\% [4], 35\% [2]). Information about non-participants is lacking, but 
higher activity levels have been associated with increased recruitment $[4,5]$, leading to potential selection bias and difficulties in generalizing results [6]. Unfortunately, these studies did not report on non-participants' health status. Whilst older people with higher activity levels tend to be healthier [7], recruiting through primary care could encourage those with more illnesses and primary care contact to respond, leading to bias in an opposing direction. Our objective was to compare the self-reported health status and physical activity levels of participants and non-participants in a primary care based physical activity study.

\section{Methods}

As part of a randomized controlled trial of different recruitment strategies to a physical activity study, 560 patients $\geq 65$ years registered with a primary health care centre (general practice) in Oxfordshire, UK were randomly selected by household [8]. Those living in care homes, those with dementia, terminal illness, poorly controlled cardiac failure or unstable angina and those housebound due to disability were first excluded by computer record search and by general (family) practitioner and district (community) nurse examination of registered patient lists. All 560 patients were invited to take part in a study measuring customary physical activity levels objectively for a 7-day period using motion sensors (accelerometers and pedometers). A random half (280) also received a 12page questionnaire with their study information, asking details about physical health (general health, limiting longstanding illness [9], disability [10], pain [11], chronic disease [12], smoking status, weight and height), depressive symptoms [13], self-reported physical activity levels $[14,15]$ and attitudes towards physical activity [16] (See Additional file 1). Subjects were encouraged to return the questionnaire, whether or not they participated in the physical activity study, thus allowing a comparison of participants and non-participants. Those participating who had not been randomized to receive a questionnaire, completed one at their baseline assessment.

\section{Ethical approval \& informed consent}

Ethics committee approval for the study was given by Oxfordshire REC A (reference no. 06/Q1604/94). The patient information sheets sent to all 560 individuals explained the study in detail, including the use of questionnaire information provided by those returning questionnaires, but not wanting to participate further. Full informed written consent was obtained from the 240 participating in the physical activity study.

\section{Analysis}

Logistic regression was used to estimate odds ratios for participating in the accelerometer study, adjusting for age and sex as appropriate and household clustering, using the cluster option in STATA 9 [16]. For age and sex comparisons the analyses were based on all 520 subjects. For analyses examining health and physical activity from the brief questionnaire, the comparison was based on all participants to the accelerometer study and those non-participants who received a questionnaire and returned it. Analyses were adjusted for age, sex and household clustering. Health measures were adjusted additionally for the effect of physical activity (walking pace and number of hours walked in the last week) and physical activity measures for the effect of health (limiting long-standing illness, number of chronic diseases, disability, falls and chronic pain) in order to see whether any effects were independent. To check that it was reasonable to combine postal questionnaires on participants with those completed at baseline assessment, a comparison of participants and non-participants as above was repeated, restricted to those randomised to postal questionnaires.

\section{Results}

Recruitment rate to the physical activity study was $43 \%(240 / 560)$. Comparison overall of participants $(n=$ $240)$ and non-participants $(n=320)$, adjusted for age, sex and household clustering, showed that males were more likely to participate OR 1.4(95\% C.I. 1.1-1.8). There was no statistically significant association between age and participating, baseline age 65-69 OR $=1$, age 70-79 OR $0.8(95 \%$ C.I. $0.5-1.1)$, age $=80$ OR 0.8(95\% C.I. 0.51.4).

Of the 280 people sent a postal questionnaire, 116 were recruited to the study and 164 were not, of these non-participants 76/164(46\%) completed the questionnaire (see Figure 1). Table 1 shows the comparison of participants ( $\mathrm{n}$ = 240) (116 from the postal questionnaire group, 124 who completed the questionnaire at baseline assessment) and non-participants $(n=76)$ who returned the questionnaire. The results for age and sex are very similar to those for participants and non-participants overall.

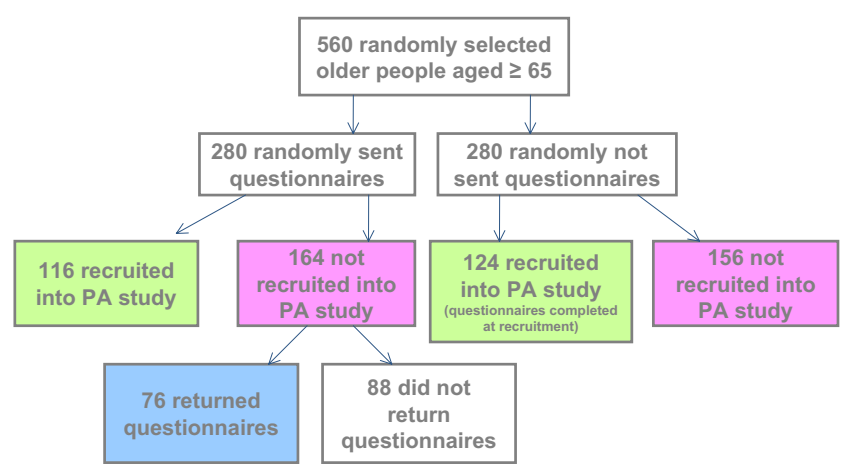

Figure I

Participant flow through the study. 
Table I: Comparison of non-participants \& participants of physical activity study amongst questionnaire responders

\begin{tabular}{|c|c|c|c|c|}
\hline & $\begin{array}{l}\text { Non-participants } N \\
=76 \mathrm{n}(\%)\end{array}$ & $\begin{array}{l}\text { Participants } N= \\
240 \text { n (\%) }\end{array}$ & $\begin{array}{l}\text { Crude OR for } \\
\text { participating ( } 95 \% \\
\text { CI) }\end{array}$ & $\begin{array}{l}\text { OR }(95 \% \mathrm{Cl}) \text { adj for } \\
\text { age, sex, household } \\
\text { clustering' }\end{array}$ \\
\hline \multicolumn{5}{|c|}{ DEMOGRAPHIC } \\
\hline \multicolumn{5}{|c|}{ Sex } \\
\hline Female & 45 (59.2) & 115 (47.9) & I & 1 \\
\hline Male & $31(40.8)$ & $125(52.1)$ & $1.6(0.9-2.7)$ & $1.6(1.1-2.4)$ \\
\hline \multicolumn{5}{|l|}{ Age } \\
\hline $65-69$ & $23(30.3)$ & $87(36.3)$ & 1 & I \\
\hline 70-79 & $40(52.6)$ & III (46.3) & 0.7 (0.4-I.3) & $0.8(0.4-1.4)$ \\
\hline 80 or more & $13(17.1)$ & $42(17.5)$ & $0.9(0.4-1.9)$ & $0.8(0.3-2.0)$ \\
\hline
\end{tabular}

\section{SELF-REPORTED} HEALTH

OR $(95 \% \mathrm{Cl})$ adj for age, sex, household clustering \& selfreported activity ${ }^{2}$

\begin{tabular}{|c|c|c|c|c|c|}
\hline \multicolumn{6}{|l|}{ General Health } \\
\hline Very good/Good & $58(84.1)$ & $200(85.1)$ & 1 & 1 & 1 \\
\hline Fair/bad & II (I5.9) & $35(14.9)$ & $0.9(0.7-1.4)$ & I.I (0.7-I.6) & I.3 (0.9-2.0) \\
\hline \multicolumn{6}{|l|}{$\begin{array}{l}\text { Limiting } \\
\text { longstanding illness }\end{array}$} \\
\hline No & $53(77.9)$ & $176(73.6)$ & 1 & 1 & 1 \\
\hline Yes & $15(22.1)$ & $65(28.6)$ & $\mathrm{I} .4(0.7-2.7)$ & $1.6(0.8-3.3)$ & $2.9(1.2-7.1)$ \\
\hline \multicolumn{6}{|l|}{ Disability } \\
\hline No & $40(53.3)$ & $125(52.7)$ & 1 & 1 & 1 \\
\hline Yes & $35(46.7$ & $112(47.3)$ & $1.0(0.6-1.7)$ & I.3 (0.7-2.5) & $2.4(1.1-5.1)$ \\
\hline \multicolumn{6}{|l|}{ Chronic pain } \\
\hline No & $46(66.7)$ & $146(63.5)$ & I & 1 & I \\
\hline Yes & $23(33.3)$ & $84(36.5)$ & I.2(0.7-2.0) & I.4 (0.7-2.6) & $2.1(1.0-4.5)$ \\
\hline \multicolumn{6}{|l|}{ Chronic disease } \\
\hline No & $25(32.9)$ & $55(22.9)$ & I & 1 & I \\
\hline Yes & $51(67.1)$ & $185(77.1)$ & $1.6(0.9-2.9)$ & $1.7(0.9-3.0)$ & $1.8(1.0-3.2)$ \\
\hline \multicolumn{6}{|l|}{ Use a walking aid } \\
\hline No & $66(89.2)$ & 217 (91.9) & I & I & I \\
\hline Yes & $8(10.8)$ & $19(8.1)$ & $0.7(0.3-1.7)$ & $0.8(0.3-2.1)$ & $1.4(0.5-3.8)$ \\
\hline \multicolumn{6}{|l|}{ Fallen in last year } \\
\hline No & $56(76.7)$ & 169 (7I.9) & I & 1 & 1 \\
\hline Yes & $17(23.3)$ & $66(28.1)$ & $1.3(0.7-2.4)$ & $1.6(0.8-2.9)$ & $2.0(1.0-4.0)$ \\
\hline \multicolumn{6}{|l|}{ Current smoker } \\
\hline No & $72(96.0)$ & $221(94.0)$ & I & I & I \\
\hline Yes & $3(4.0)$ & $14(6.0)$ & $1.5(0.4-5.4)$ & $1.3(0.3-5.1)$ & $1.5(0.4-5.1)$ \\
\hline \multicolumn{6}{|l|}{ Body Mass Index } \\
\hline Normal weight & $28(46.7)$ & $97(43.1)$ & I & I & I \\
\hline Overweight or obese & $32(53.3)$ & $128(56.9)$ & $1.2(0.7-2.0)$ & I.2 (0.7-2.4) & $1.4(0.7-2.6)$ \\
\hline \multicolumn{6}{|l|}{$\begin{array}{l}\text { Geriatric } \\
\text { Depression Score }\end{array}$} \\
\hline$<4$ & $67(88.2))$ & $213(89.5)$ & I & I & I \\
\hline 4 or more & $9(11.8)$ & $25(10.5)$ & $0.9(0.4-2.0)$ & $0.9(0.4-2.0)$ & I.I (0.5-2.5) \\
\hline $\begin{array}{l}\text { SELF-REPORTED } \\
\text { ACTIVITY }\end{array}$ & & & & & $\begin{array}{l}\text { OR }(95 \% \mathrm{Cl}) \\
\text { age, sex, hous } \\
\text { clustering \& s } \\
\text { reported hea }\end{array}$ \\
\hline \multicolumn{6}{|l|}{$\begin{array}{l}\text { Walking pace } \\
\text { compared to } \\
\text { others }\end{array}$} \\
\hline Slower/much slower & $16(21.3)$ & $22(9.4)$ & I & I & 1 \\
\hline About the same & $34(45.3)$ & $100(42.5)$ & $2.1(1.1-4.5)$ & $1.9(1.0-4.2)$ & $4.6(1.7-12.5)$ \\
\hline Faster/much faster & $25(33.3)$ & I I $3(48.1)$ & $3.3(1.5-7.1)$ & $3.2(1.4-7.7)$ & $10.4(3.2-33.3)$ \\
\hline
\end{tabular}


Table I: Comparison of non-participants \& participants of physical activity study amongst questionnaire responders (Continued)

\begin{tabular}{|c|c|c|c|c|c|}
\hline \multicolumn{6}{|l|}{$\begin{array}{l}\text { Hours walked in } \\
\text { last week? }\end{array}$} \\
\hline None & $24(31.6)$ & $37(15.4)$ & 1 & 1 & 1 \\
\hline Up to 2 hours & $25(32.9)$ & $87(36.3)$ & $2.3(1.1-4.5)$ & $2.3(1.1-4.7)$ & $2.5(1.1-5.6)$ \\
\hline More than 2 hours & $27(35.5)$ & $116(48.3)$ & $2.8(1.4-5.4)$ & $2.7(1.3-5.5)$ & $2.8(1.3-6.1)$ \\
\hline \multicolumn{6}{|l|}{$\begin{array}{l}\text { Average hours } \\
\text { gardening weekly }\end{array}$} \\
\hline None & $19(25.3)$ & $23(10.0)$ & 1 & 1 & 1 \\
\hline Up to $3.5 \mathrm{hrs} /$ week & $30(40.0)$ & $102(44.4)$ & $2.8(1.4-5.8)$ & $2.7(1.3-5.6)$ & $2.7(1.1-6.9)$ \\
\hline$>3.5 \mathrm{hrs} /$ week & $26(34.7)$ & $105(45.7)$ & $3.3(1.6-7.0)$ & $2.8(1.3-6.3)$ & $3.3(1.2-8.7)$ \\
\hline \multicolumn{6}{|c|}{$\begin{array}{l}\text { Activity compared } \\
\text { to others }\end{array}$} \\
\hline $\begin{array}{l}\text { Less active or the } \\
\text { same }\end{array}$ & $27(35.5)$ & $49(20.6)$ & I & 1 & 1 \\
\hline More active & $33(43.4)$ & II 6 (48.7) & $1.9(1.1-3.6)$ & $1.9(1.0-3.6)$ & $2.2(1.0-4.5)$ \\
\hline Far more active & $16(21.1)$ & $73(30.7)$ & $2.5(1.2-5.1)$ & $2.3(1.1-5.2)$ & $3.1(1.3-7.0)$ \\
\hline \multicolumn{6}{|l|}{ Do you cycle? } \\
\hline No & $63(87.5)$ & 187 (78.9) & 1 & 1 & 1 \\
\hline Yes & $9(12.5)$ & $50(2 I .1)$ & $1.9(0.9-4.0)$ & $1.7(0.7-4.1)$ & $2.0(0.8-5.1)$ \\
\hline \multicolumn{6}{|c|}{ Do you walk a dog? } \\
\hline No & $67(88.2)$ & $184(78.6)$ & 1 & 1 & 1 \\
\hline Yes & $9(11.8)$ & $50(21.4)$ & $2.0(0.9-4.3)$ & $2.0(0.8-5.2)$ & $2.0(0.7-5.2)$ \\
\hline \multicolumn{6}{|l|}{$\begin{array}{l}\text { Do you do heavy } \\
\text { housework? }\end{array}$} \\
\hline No & $23(34.3)$ & $50(22.7)$ & I & 1 & 1 \\
\hline Yes & $44(65.7)$ & $170(77.3)$ & $1.8(1.0-3.2)$ & $1.7(1.0-3.2)$ & $2.3(1.2-4.5)$ \\
\hline \multicolumn{6}{|l|}{$\begin{array}{l}\text { Positive attitudes } \\
\text { towards activity? }\end{array}$} \\
\hline Low & $35(53.9)$ & $73(31.6)$ & I & I & 1 \\
\hline High & $30(46.2)$ & $158(68.4)$ & $2.5(1.4-4.4)$ & $2.5(1.4-4.5)$ & $3.4(1.8-6.6)$ \\
\hline
\end{tabular}

'Household clustering - adjusted for the clustering by 237 households.

2Self-reported physical activity- adjusted for effect of walking pace and hours walked in last week

${ }^{3}$ Geriatric Depression Score 15 items, using cut-off $<4 / \geq 4$, which gives a sensitivity of $91 \%$ and specificity of $72 \%$ for detecting major depression [13].

${ }^{4}$ Self-reported health - adjusted for effect of limiting longstanding illness, chronic disease, disability, falls \& pain.

After adjusting for age, sex and household clustering, participants tended to report more health problems than non-participants for most variables, (but no differences were statistically significant at $\mathrm{p}=0.05)$. The exceptions were: use of a walking aid which showed a non-significant effect in the opposite direction; and depression score which was unrelated to participation. Adjusting for selfreported physical activity levels strengthened the associations between poorer health and participating such that those reporting limiting longstanding illness, disability, chronic pain, chronic disease and a fall in the last year were more likely to participate.

After adjusting for age, sex and household clustering, participants reported more physical activity than non-participants for all measures and more positive attitudes towards physical activity. Apart from cycling and dogwalking, where numbers were small, these differences were all statistically significant and several showed doseresponse effects. Adjusting these estimates for selfreported health strengthened these effects still further.
Analyses restricted to participants (116) and non-participants (76) who returned the postal questionnaire showed very similar findings in terms of effect estimates to those presented, based on all questionnaire completers. Although the confidence intervals were wider due to smaller numbers, several associations with participation reached statistical significance at $\mathrm{p}=0.05$ for both health, e.g. disability, adjusted OR 2.4 (05\% C.I. 1.1-5.5) and physical activity variables, e.g. higher activity levels than others, adjusted OR 3.1 (95\% C.I. 1.1-8.7).

\section{Discussion}

Recruitment to our motion sensor activity study was $43 \%$, higher than for physical activity intervention studies in this age group [2-4], but lower than for surveys [1,2]. With this recruitment level, estimation of potential nonresponse bias is important.

Our findings suggest two separate issues leading to potential bias. Firstly, participants were more physically active than non-participants (consistent with men being more 
likely to participate). This has been reported in other physical activity studies in older people [3-5]. Secondly, participants reported more health problems than nonparticipants. This effect opposes the physical activity effect, and was much clearer after controlling for selfreported physical activity. At first, these findings seem counter-intuitive. Other studies in older people have reported that participants have better health than nonparticipants [18-20], suggesting a "healthy volunteer" effect, although Ives et al found participants were more likely to have a disease history and use health services more [21]. However, it seems plausible that recruiting older people to studies through primary care may lead to those with increased contact with primary care (ie more illnesses) to be more likely to take part. This fits with other work showing that older primary care patients with poorer physical and psychological health and greater primary care service use were more likely to give consent for their health records to be accessed for research [22]. Unfortunately, the other primary care based studies showing differences in physical activity levels between participants and non-participants did not report on health or functional ability [3-5].

An important weakness of our study was that self-reported health and physical activity details were only available on those non-participants who completed the questionnaire. The similarities seen in age and sex comparisons between participants and non-participants overall and in those responding to the questionnaire is reassuring and suggests that the non-participant questionnaire responders are representative of non-participants, at least in terms of age and sex, although they could still differ in other important ways (such as activity level or health) that we lack information on. The similarities found when restricting analyses to only those sent postal questionnaires, confirms that it was reasonable to include participants in the analysis who completed the questionnaire at their baseline assessment.

\section{Conclusion}

Physical activity studies on older people recruited from primary care settings may be biased by two opposing issues which need consideration when generalizing the results: a strong bias towards participants being more physically active, and a weaker bias towards participants having more health problems and therefore likely primary care contact. This latter bias could be used to advantage when considering interventions to increase physical activity, where those who are least active and those with more physical health problems need targeting most.

\section{Competing interests}

The authors declare that they have no competing interests.

\section{Authors' contributions}

TJH, CRV and DGC designed the study. TJH and RA collected data. TJH, IMC and DGC were involved in analysis and interpretation of data. All authors were involved in drafting the manuscript and revising it critically for important intellectual content. All authors have given final approval of the version to be published.

\section{Additional material}

\section{Additional file 1}

supplementary questionnaire harris2008. Questionnaire on health and self-report physical activity levels.

Click here for file

[http://www.biomedcentral.com/content/supplementary/14712458-8-182-S1.doc]

\section{Acknowledgements}

We are grateful to all the partners, staff and patients of Sonning Common Health Centre, Oxfordshire, UK for their support with this study. Funding for the study was provided by the Thames Valley Primary Care Research Partnership (WCRM03). The sponsors played no role in the design, execution, analysis \& interpretation of data or in the writing of the manuscript or the decision to submit the manuscript for publication.

\section{References}

I. Crombie IK, Irvine L, Williams B, et al:: Why older people do not participate in leisure time physical activity: a survey of activity levels, beliefs and deterrents. Age Ageing 2004, 33:287-92.

2. Stevens W, Hillsdon M, Thorogood M, McArdle D: Cost-effectiveness of a primary care based physical activity intervention in 45-74 year old men \& women: a randomised controlled trial. BrJ Sports Med 1998, 32:236-4I.

3. Munro JF, Nicholl JP, Brazier JE, Davey R, Cochrane T: Cost effectiveness of a community based exercise programme in over 65 year olds: cluster randomised trial. J Epidemiol Community Health 2004, 58: 1004-10.

4. Halbert JA, Silagy CA, Finucane P, Withers RT, Hamdorf PA: Recruitment of older adults for a randomized, controlled trial of exercise advice in a general practice setting. J Am Geriatr Soc 1999, 47:477-8I.

5. Crombie IK, McMurdo ME, Irvine L, Williams B: Overcoming barriers to recruitment in health research: concerns of potential participants need to be dealt with. BMJ 2006, 333:398.

6. Tai SS, Gould M, lliffe S: Promoting healthy exercise among older people in general practice: issues in designing and evaluating therapeutic interventions. British Journal of General Practice 1997, 47: I1 19-22.

7. Ettinger WH Jr: Physical activity and older people: a walk a day keeps the doctor away. J Am Geriatr Soc 1996, 44:207-8.

8. Harris TJ, Victor CR, Carey IM, Adams R, Cook DG: Optimising recruitment into a study of physical activity in older people: a randomised controlled trial of different approaches. Age \& Ageing in press. 2008

9. Joint Health Surveys Unit: Health Survey for England 1998. In Methodology and Documentation Volume 2. London, The Stationery Office; 1999.

10. McGee MA, Johnson A, Kay D: The Medical Research Council Cognitive Functioning and Ageing Study (MRC CFAS). The description of activities of daily living in five centres in England and Wales. Age \& Ageing 1998, 27:605-13.

II. Ware JE, Sherbourne CD: The MOS 36-item short form health survey: conceptual framework and item selection. Med Care 1992, 30:473-83. 
12. Roberts RE, Kaplan GA, Shema SJ, Strawbridge WJ: Prevalence and correlates of depression in an aging cohort: the Alameda County Study. J Gerontol B Psychol Sci Soc Sci 1997, 52:S252-S258.

13. D'Ath P, Katona P, Mullan E, Evans S, Katona C: Screening, detection and management of depression in elderly primary care attenders. I: The acceptability and performance of the 15 item Geriatric Depression Scale (GDSI5) \& the development of short versions. Fam Pract 1994, I I:260-6.

14. Caspersen C], Bloemberg BP, Saris WH, Merritt RK, Kromhout D: The prevalence of selected physical activities and their relation with coronary heart disease risk factors in elderly men: the Zutphen Study, 1985. Am J Epidemiol 199I, I33:1078-92.

15. Washburn RA, Smith KW, Jette AM, Janney CA: The Physical Activity Scale for the Elderly (PASE): development and evaluation. I Clin Epidemiol 1993, 46: I53-62.

16. Jette AM, Rooks D, Lachman M, Lin TH, Levenson C, Heislein D, et al: Home-based resistance training: predictors of participation and adherence. Gerontologist 1998, 38:4I2-2I.

17. STATA 9.0 Statistics/Data Analysis. College Station, Texas, USA, Statacorp; 2005.

18. van Heuvelen MJ, Hochstenbach JB, Brouwer WH, de Greef MH, Zijlstra GA, van Jaarsveld E, et al.: Differences between participants and non-participants in an RCT on physical activity and psychological interventions for older persons. Aging Clin Exp Res 2005, I 7:236-45.

19. Hebert R, Bravo G, Korner-Bitensky N, Voyer L: Refusal and information bias associated with postal questionnaires and faceto-face interviews in very elderly subjects. J Clin Epidemiol 1996, 49:373-81.

20. Wagner EH, Grothaus LC, Hecht JA, LaCroix AZ: Factors associated with participation in a senior health promotion program. Gerontologist 1991, 3 I:598-602.

21. Ives DG, Traven ND, Kuller LH, Schulz R: Selection bias and nonresponse to health promotion in older adults. Epidemiology 1994, 5:456-61.

22. Harris T, Cook DG, Victor C, Beighton C, DeWilde S, Carey I: Linking questionnaires to primary care records: factors affecting consent in older people. J Epidemiol Community Health 2005, 59:336-8.

\section{Pre-publication history}

The pre-publication history for this paper can be accessed here:

http://www.biomedcentral.com/1471-2458/8/182/pre

pub http.//www.biomedcentral.com/1471-2458/8/182 